\title{
Evaluation of the prognostic benefit of identifying the probable primary site in cancer of unknown primary
}

\author{
Joyutpal Das* and Shahid Gilani\# \\ Cancer centre, University Hospital of North Midlands NHS Trust, \\ Royal Stoke University Hospital, \\ Newcastle Road, Stoke-on-Trent, UK \\ ST4 6QG Tel: + 44 (0)1782 715444
}

Received 23 July 2015; Accepted 26 October 2015

\begin{abstract}
With the development of site-specific cancer therapy, identifying the primary origin allows the oncologist to personalise therapy for patients with the cancer of unknown primaries (CUPs). At present, immunohistochemistry (IHC) screening is the standard method used to postulate the primary site in CUP. In this retrospective study, we evaluated the prognostic benefit of identifying the primary site in CUP. All 84 patients who presented with suspected CUPs to the Royal Stoke University Hospital between 2011 and 2012, were included in our study. Forty-eight percent (40/84) of these patients were unable to undergo necessary investigations to identify primary sites because of poor performance status. IHC screening was able to postulate the primary site in $59 \%(26 / 44)$ of the remaining confirmed CUP patients. Therefore, the primary site was not identified in a significant proportion of suspected CUP patients. The median survival of confirmed CUP patients with probable primary sites was 2.0 months (95\% confidence interval (CI): 1.2 to 2.9 months), whereas the median survival of confirmed CUP patients with no probable primary site was 4.1 months (95\% Cl: 1.5 to 9.7 months). This difference in survival time was statistically significant. In addition, using the Cox regression model we found that confirmed CUP patients with primary sites had prognostically unfavourable diseases with a shorter median survival, regardless of the age of disease onset, gender, sites of metastases or number of metastases. One approach to improve the survival would be to start systemic therapy at the earliest possible opportunity rather than waiting for all investigation results such as IHC.
\end{abstract}

Keywords: Cancer of Unknown Primary • Immunohistochemistry • Prognosis • Prognostic factor

(C) De Gruyter Open

\section{Abbreviations}

\author{
Cancer of Unknown Primary - CUP \\ Immunohistochemistry - IHC \\ Confidence Interval - $\mathrm{Cl}$
}

\section{Introduction}

Cancer of unknown primary (CUP) is a heterogeneous group of metastatic tumours in the absence of discernible primary site following the standardised diagnostic work-up. CUPs are by definition metastatic diseases and generally have poor prognosis (1). Patients with CUPs have shorter survival than those with metastases from known primaries (2). With the advance of sophisticated radiological, laboratory and pathological investigations, the incidence rate of CUP is decreasing over the last few decades (3-5).
Despite this progress in medical science, the anatomical site remains unknown in a significant proportion of CUPs even after the autopsy (6).

Besides the dormancy of primary tumour, the development of early systemic metastases and treatment resistance are other hallmarks of CUP. The underlying molecular aberrations that characterises CUP is poorly understood. There is still no consensus as to whether it is clinicopathologically a completely distinct entity or it is a group of tumours with unidentified primaries (7). Over the years, many prognostic factors have been identified that are associated with poor survival in CUPs, such as male gender, increasing number of metastatic sites, liver metastasis, bone metastasis, adenocarcinoma, poor performance status, leucocytosis, lymphopenia, raised serum alkaline phosphatase level, hypercalcaemia, hypoalbuminemia and high serum lactate dehydrogenase level (8-22). 
Only a minority of CUP patients belongs to clinicopathological subsets with favourable prognosis. The majority of CUPs harbour tumours that are relatively unresponsive to systemic therapy and have a dismal prognosis $(1,23,24)$. With the development of sitespecific therapy, the CUP is becoming the 'poster child' for personalised medicine and therefore, identifying the primary origin is becoming ever more important (25-27). At present, the immunohistochemistry (IHC) screening is a standard method that is readily used to postulate the putative primary origin in CUP. Depending on the IHC profile, the CUP can be divided into two subclasses: 1) CUP with probable primary site, in which the primary site could be postulated from IHC profile and 2) CUP with no probable primary site, in which the primary site remains unknown even after the exhaustive IHC screening (28).

As CUP has poor prognosis and is relatively less responsive to systemic therapy, there is a lack of consensus on the extent of investigations that should be undertaken to identify the primary origin of cancer $(29,30)$. On one hand, identifying the primary site allows the physician to tailor the treatment for an individual patient $(1,28,31)$. On the other hand, extensive diagnostic tests to identify the primary origin of cancer cost money and time $(29,30)$.

In this study, we evaluated the prognostic benefit of identifying the probable primary site in CUP. We examined the impact of identifying the putative primary site on survival by assessing whether there was a difference in the length of survival between CUP with probable primary site and CUP with no probable primary site. We then further assessed the value of identifying the probable primary site in CUP as a prognostic factor using the Cox regression model.

\section{Patients and Methods}

\section{Patient population}

In this retrospective study, we excluded CUP from probable head and neck origin and also from other favourable subsets (32). A total of 84 patients who presented with suspected CUPs to the Royal Stoke University Hospital (formally known as University Hospital of North Staffordshire) between 2011 and 2012, were included in our study.

Initially, these suspected CUP patients were divided into two groups: provisional and confirmed CUPs. Suspected CUP patients with poor performance status, who were unable to undergo all necessary investigations to identify probable primary site, were categorised as provisional CUPs. Patients with confirmed CUPs underwent extensive investigations including IHC screening to postulate the primary site. On the basis of IHC profile, confirmed CUP patients were further divided into two subclasses: confirmed CUP with probable primary site and confirmed CUP with no probable primary site.

\section{Statistical analysis}

In this study, we calculated the length of survival from the day of diagnosis. We monitored their survival over a 36-month period. In order to measure the length of survival for patients who did not die, the survival times were censored at the time at which they were last known to be alive. The median survival time was calculated along with a 95\% confidence interval $(\mathrm{Cl})$. Kaplan-Meier graphs were used to illustrate patient survival.

We used the Cox regression model to identify clinical variables that were associated with poor survival in CUP patients. Initially, the association between each variable and survival time was examined separately in a series of univariable analyses. As several of covariates were correlated, the joint association was examined in a multivariable analysis. To restrict the number of variables at this stage of the analysis for the prognostic factors of confirmed CUP, only factors showing some association in univariable analyses $(p<0.2)$ were included.

\section{Results}

Eighty four suspected CUP patients that were included in our study, represented $1 \%$ of the total number of patients with malignancies. Forty-eight percent (40/84) of these patients, who had poor performance status to undergo all necessary investigations, were categorised as provisional CUPs. After extensive investigations, only $52 \%$ (44/84) of these patients had the diagnosis of confirmed CUPs.

The demographic and disease-related characteristics are listed in Tables 1 and 2. In general, the CUP population had marginally higher proportion of male than the total cancer population (Table 1). There was also disproportionately higher number of patients aged 70 or over in the CUP population than the total cancer population (Table 1).

In this study, we then compared the length of survival between patients with provisional and confirmed CUPs. About $90 \%$ of our study population died by the end of 36-month follow-up period in both provisional and confirmed CUP groups. Provisional CUP patients, who had poorer performance status, had a significantly shorter length of median survival than confirmed CUP patients (Figure 1). The median survival of provisional CUP 
Table 1. Demographics of 84 patients with suspected CUPs and the total cancer population.

\begin{tabular}{|c|c|c|c|}
\hline Age & Male (\%) & Female (\%) & Total (\%) \\
\hline & \multicolumn{2}{|c|}{ Total cancer population } & \\
\hline $0-24$ & $26(0.3)$ & $27(0.3)$ & $53(0.7)$ \\
\hline $25-49$ & $230(2.9)$ & 459 (5.9) & $689(8.8)$ \\
\hline $50-69$ & $1633(20.8)$ & $1546(19.7)$ & $3179(40.6)$ \\
\hline$\geq 70$ & 2220 (28.3) & $1692(21.6)$ & $3912(49.9)$ \\
\hline \multirow[t]{2}{*}{ Total } & 4109 (52.5) & 3724 (47.5) & $7833(100)$ \\
\hline & \multicolumn{2}{|c|}{ Provisional CUP } & \\
\hline $0-24$ & $0(0)$ & $0(0)$ & $0(0)$ \\
\hline $25-49$ & $0(0)$ & $0(0)$ & $0(0)$ \\
\hline $50-69$ & $5(12.5)$ & $3(7.5)$ & $8(20)$ \\
\hline$\geq 70$ & $21(52.5)$ & $11(27.5)$ & $32(80)$ \\
\hline \multirow[t]{2}{*}{ Total } & $26(65)$ & $14(35)$ & $40(100)$ \\
\hline & \multicolumn{2}{|c|}{ Confirmed CUP } & \\
\hline $0-24$ & $0(0)$ & $0(0)$ & $0(0)$ \\
\hline $25-49$ & $3(6.8)$ & $1(2.3)$ & $4(9.1)$ \\
\hline $50-69$ & $8(18.2)$ & $7(15.9)$ & $15(34.1)$ \\
\hline$\geq 70$ & $15(34.1)$ & $10(22.7)$ & $25(56.8)$ \\
\hline Total & $26(59.1)$ & $18(40.9)$ & $44(100)$ \\
\hline
\end{tabular}

Table 2. The major sites and number of metastases in 44 confirmed CUP patients.

\begin{tabular}{c|c}
\hline Site of metastasis & N (\%) \\
\hline \hline Lymph nodes & $29(66)$ \\
Liver & $18(41)$ \\
Lung or pleura & $19(43)$ \\
Peritoneum or ascites & $12(27)$ \\
Bone & $11(25)$ \\
Number of metastases & $\mathbf{N}(\%)$ \\
$\leq 2$ & $21(48)$ \\
$>2$ & $23(52)$ \\
\hline
\end{tabular}

patients was 0.8 month ( $95 \%$ Cl: 0.5 to 1.4 months), whereas the median survival of the confirmed C UP patients was 2.1 months (95\% Cl: 1.6 to 2.9 months). These findings were statistically significant.

Consistent with previous studies (33-35), IHC screening was able to postulate probable primary sites

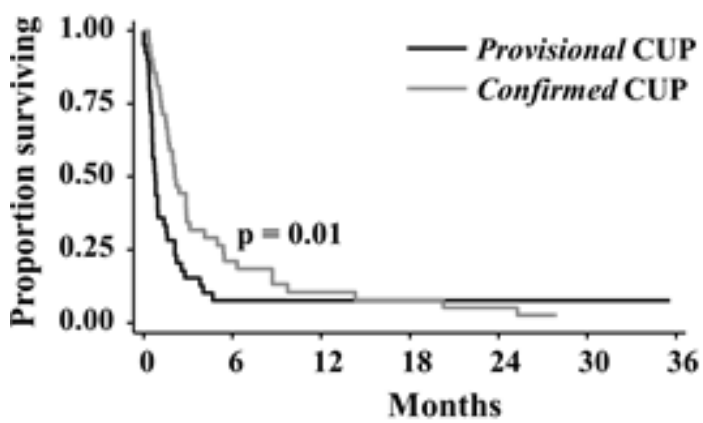

Figure 1. Kaplan-Meier survival curves of 40 provisional CUP patients and 44 confirmed CUP patients.

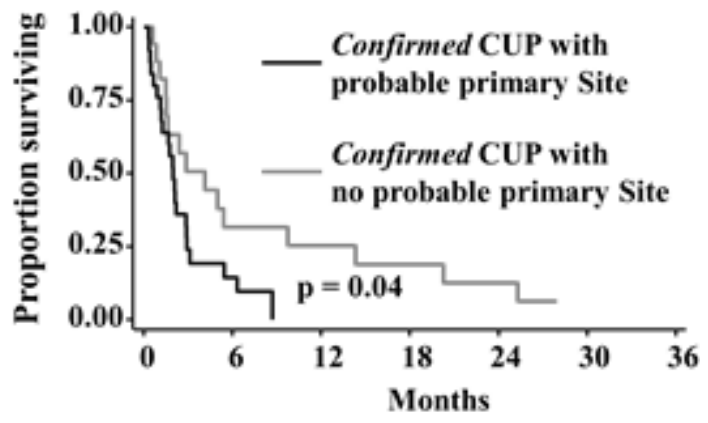

Figure 2. Kaplan-Meier survival curves of 26 confirmed CUP patients with probable primary sites and 18 confirmed CUP patients with no probable primary site.

in $59 \%(26 / 44)$ of confirmed CUP cases. Interestingly, the median survival of confirmed CUP patients with no probable primary site was higher than those with probable primary sites (figure 2). The median survival of the confirmed CUP patients with no probable primary site was 4.1 months (95\% Cl: 1.5 to 9.7 months) and the median survival of the confirmed CUP patients with probable primary sites was 2.0 months $(95 \% \mathrm{Cl}$ : 1.2 to 2.9 months). These findings were also statistically significant.

We then examined the association of clinical variables, such as the age of disease onset, gender, sites of metastases, the number of metastases and CUP classification based on IHC profile with the survival time of confirmed CUP patients, using the Cox regression model. In this analysis, we used CUP classification based on IHC profile rather than histological diagnosis, as identifying the putative primary site would allow tailoring therapy on individual basis $(1,28,31)$. The univariable analyses suggested that liver metastasis, involvement of more than two metastatic sites and CUP with probable primary site had poor prognosis (Table 3). Subsequently, a multivariable analysis was performed, which showed only liver metastasis and 
Table 3. Univariable analysis with clinical variables in 44 confirmed CUP patients.

\begin{tabular}{|c|c|c|c|}
\hline Variable & Category & $\begin{array}{l}\text { Median survival, } \\
\left.\text { months (95\% } \mathrm{Cl}^{*}\right)\end{array}$ & $\begin{array}{c}\mathbf{p} \\
\text { value }\end{array}$ \\
\hline Age & $\begin{array}{l}<70 \\
\geq 70\end{array}$ & $\begin{array}{l}2.8(1.5,3.1) \\
2.0(1.1,5.0)\end{array}$ & 0.82 \\
\hline Gender & $\begin{array}{c}\text { Female } \\
\text { Male }\end{array}$ & $\begin{array}{l}1.7(0.6,2.9) \\
2.4(1.5,5.4)\end{array}$ & 0.19 \\
\hline Lymph nodes & $\begin{array}{l}\text { No } \\
\text { Yes }\end{array}$ & $\begin{array}{l}2.1(1.1,2.9) \\
2.4(1.5,5.0)\end{array}$ & 0.18 \\
\hline Liver & $\begin{array}{l}\text { No } \\
\text { Yes }\end{array}$ & $\begin{array}{l}3.1(1.5,6.3) \\
1.7(0.8,2.1)\end{array}$ & 0.004 \\
\hline Lung or pleura & $\begin{array}{l}\text { No } \\
\text { Yes }\end{array}$ & $\begin{array}{l}2.4(1.1,4.1) \\
1.9(1.5,5.4)\end{array}$ & 0.83 \\
\hline $\begin{array}{l}\text { Peritoneum or } \\
\text { Ascites }\end{array}$ & $\begin{array}{l}\text { No } \\
\text { Yes }\end{array}$ & $\begin{array}{l}2.8(1.5,5.4) \\
1.9(0.4,2.1)\end{array}$ & 0.06 \\
\hline Bone & $\begin{array}{l}\text { No } \\
\text { Yes }\end{array}$ & $\begin{array}{l}2.8(1.2,5.0) \\
1.7(0.3,2.1)\end{array}$ & 0.07 \\
\hline $\begin{array}{l}\text { Number of } \\
\text { metastases }\end{array}$ & $\begin{array}{l}\leq 2 \\
>2\end{array}$ & $\begin{array}{l}4.1(1.2,8.7) \\
1.9(1.5,2.2)\end{array}$ & 0.007 \\
\hline $\begin{array}{c}\text { CUP } \\
\text { Classification }\end{array}$ & $\begin{array}{c}\text { No probable } \\
\text { primary site } \\
\text { Probable } \\
\text { primary site }\end{array}$ & $\begin{array}{l}4.1(1.5,9.7) \\
2.0(1.2,2.9)\end{array}$ & 0.04 \\
\hline
\end{tabular}

*Confidence interval

identification of probable primary site from IHC profile were independently associated with poor survival in patients with confirmed CUPs (Table 4). This risk of death at any time for the confirmed CUP patients with liver metastases was three times higher than those without liver metastasis. Also the risk of death at any time for the confirmed CUP patients with probable primary sites was two times higher than those with no probable primary site.

In our study population, only two CUP patients with no probable primary site and three CUP patients with probable primary sites received systemic chemotherapies. Also eight CUP patients with no probable primary site and six CUP patients with probable primary sites received palliative radiotherapies for the symptom control, such as bone pain and spinal cord compression. The number of patients in these
Table 4. Multivariable analysis with clinical variables in 44 confirmed CUP patients.

\begin{tabular}{l|lcc}
\hline Variable & Category & $\begin{array}{c}\text { Hazard Ratio } \\
\left(\mathbf{9 5 \%} \mathbf{C l}^{*}\right)\end{array}$ & p value \\
\hline \hline Liver metastasis & No & 1 & 0.005 \\
& Yes & $2.97(1.38,6.40)$ & \\
CUP classification & $\begin{array}{l}\text { No probable } \\
\text { primary site }\end{array}$ & 1 & 0.04 \\
& $\begin{array}{l}\text { Probable } \\
\text { primary site }\end{array}$ & $2.14(1.03,4.47)$ & \\
\hline
\end{tabular}

subsets receiving treatments were too small to assess the impact of treatment on their survival.

\section{Discussion}

Our study has depicted the natural history of CUP. About half of our suspected CUP patients had poor performance status to undergo all necessary investigations for identifying the primary site. Although histopathological evaluation were required to confirm the diagnosis of CUP, one US study reported that about one-third of these patients didn't have histopathological investigations (4). The remaining half of our CUP patients underwent extensive investigations and primary sites were postulated in only $59 \%$ of those cases. In previous studies, IHC had similar rate of success in postulating the primary site $(34,35)$. Therefore, the primary site could not be identified in a significant proportion of our CUP patients. Furthermore, we also noticed that the confirmed CUP patients with probable primary sites had shorter median survival than those with no probable primary site. One approach to improve survival would be to start treatment at the earliest possible opportunity rather than waiting for investigation results such as $\mathrm{IHC}$ profile.

IHC screening, which is costly and takes time, requires special expertise and may not be available in all cancer centres $(35,36)$. Although identifying the primary site would allow tailoring personalised therapy, it may be time consuming and expensive. From our data, it was unclear whether waiting for the results of IHC screening had any detrimental effect on the patient survival. In addition, it is also distressing for patients with CUPs to undergo all those investigations with looming uncertain futures: at the end of all these investigations, the primary site may not be identified and also there are very limited treatment options available for CUP (37). Anxiety and depression are more prevalent in patients with CUPs 
than other cancers (38). Therefore, only those CUP patients, who are suitable for treatments should be subjected to extensive investigations to identify their putative primary sites.

The prognostic factors, associated with poor survival in CUPs are male gender, increasing number of metastases, liver metastasis, bone metastasis, adenocarcinoma, poor performance status, leucocytosis, lymphopenia, raised serum alkaline phosphatase level, hypercalcaemia, hypoalbuminemia and high serum lactate dehydrogenase level (8-22). Some of these clinical variables are interdependent. It was not surprising that in our study the provisional CUP patients with poor performance status had a significantly shorter median survival than the confirmed CUP patients. Consistent with previous studies $(9,10)$, we also found that the liver metastasis was a poor prognostic marker.

Unlike other studies, we included CUP classification based on IHC profile instead of histological diagnosis in our analysis. Interestingly, we observed that confirmed CUP cases in which primary sites could be postulated using IHC profile, had prognostically unfavourable diseases regardless of the age on disease onset, gender, sites of metastases or the number of metastases.

\section{References}

[1] Fizazi K, Greco FA, Pavlidis N, Pentheroudakis G. Cancers of unknown primary site: ESMO Clinical Practice Guidelines for diagnosis, treatment and follow-up. Ann Oncol [Internet]. 2011 Sep [cited 2015 May 22];22 Suppl 6:vi64-8. Available from: http://www.ncbi.nlm.nih.gov/pubmed/21908507

[2] Riihimäki M, Thomsen H, Hemminki A, Sundquist K, Hemminki K. Comparison of survival of patients with metastases from known versus unknown primaries: survival in metastatic cancer. BMC Cancer [Internet]. 2013 Jan [cited 2015 Sep 30];13:36. Available from: http://www.pubmedcentral.nih.gov/articlerender.fcg i? artid=3565900\&tool=pmcentrez\&rendertype=abs tract

[3] Brustugun OT, Helland Å. Rapid reduction in the incidence of cancer of unknown primary. A population-based study. Acta Oncol [Internet]. 2014 Jan [cited 2015 Sep 29];53(1):134-7. Available from: http://www.ncbi.nlm.nih.gov/pubmed/23550957

[4] Mnatsakanyan E, Tung W-C, Caine B, SmithGagen J. Cancer of unknown primary: time trends in incidence, United States. Cancer Causes Control [Internet]. 2014 Jun [cited 2015 Sep 29];25(6):747-
In other words, CUP patients with probable primary sites who were suitable for site-specific treatments had prognostically unfavourable diseases with shorter median survival.

In summary, about half of our suspected CUP patients were too frail to undergo all necessary investigations to identify probable primary sites. IHC screening was successful in postulating the putative primary site in less than two-third of these remaining patients. IHC screening can be used as a tool to identify the prognostically unfavourable subset of CUP. Although we had a small data set, we found that the CUP patient with probable primary site had a prognostically unfavourable disease with shorter median survival. One approach to improve the survival would be to start systemic therapy at the earliest possible opportunity rather than waiting for all investigation results such as IHC. In future, further studies are required to assess whether this proposed approach of treatment would improve their prognosis.

\section{Conflict of interest statement}

None declared.
57. Available from: http://www.ncbi.nlm.nih.gov/ pubmed/24710663

[5] Urban D, Rao A, Bressel M, Lawrence YR, Mileshkin L. Cancer of unknown primary: a population-based analysis of temporal change and socioeconomic disparities. Br J Cancer [Internet]. 2013 Sep 3 [cited 2015 Sep 29];109(5):1318-24. Available from: http://www.pubmedcentral.nih.gov/articlerender.fcg $i$ ?artid $=3778275 \&$ tool=pmcentrez\&rendertype $=$ abs tract

[6] Schwartz AM, Harpaz N. A primary approach to cancers of unknown primary. J Natl Cancer Inst [Internet]. 2013 Jul5 [cited 2015 Jul 31];105(11):759 61. Available from: http://www.ncbi.nlm.nih.gov/ pubmed/23641044

[7] Pentheroudakis G, Briasoulis E, Pavlidis N. Cancer of Unknown Primary Site: Missing Primary or Missing Biology? Oncologist [Internet]. 2007 Apr 1 [cited 2015 Sep 30];12(4):418-25. Available from: http://www.ncbi.nlm.nih.gov/pubmed/17470684

[8] Culine S, Kramar A, Saghatchian M, Bugat R, Lesimple T, Lortholary A, et al. Development and validation of a prognostic model to predict the 
length of survival in patients with carcinomas of an unknown primary site. J Clin Oncol [Internet]. 2002 Dec 15 [cited 2015 Jun 1];20(24):4679-83. Available from: http://www.ncbi.nlm.nih.gov/ pubmed/12488413

[9] Abbruzzese JL, Abbruzzese MC, Hess KR, Raber MN, Lenzi R, Frost P. Unknown primary carcinoma: natural history and prognostic factors in 657 consecutive patients. J Clin Oncol [Internet]. 1994;12(6):1272-80. Available from: http://www. ncbi.nlm.nih.gov/pubmed/8201389

[10] Hess KR, Abbruzzese MC, Lenzi R, Raber MN, Abbruzzese JL. Classification and regression tree analysis of 1000 consecutive patients with unknown primary carcinoma. Clin Cancer Res [Internet]. 1999;5(11):3403-10. Available from: http://www. ncbi.nlm.nih.gov/pubmed/10589751

[11] Trivanovic D, Petkovic M, Stimac D. Low serum albumin levels and liver metastasis are powerful prognostic markers for survival in patients with carcinomas of unknown primary site. Cancer [Internet]. 2007 Jun 15 [cited 2015 Sep 30];109(12):2623-4; author reply 2624. Available from: http://www.ncbi.nlm.nih.gov/ pubmed/17487858

[12] Seve P, Ray-Coquard I, Trillet-Lenoir V, Sawyer M, Hanson J, Broussolle C, et al. Low serum albumin levels and liver metastasis are powerful prognostic markers for survival in patients with carcinomas of unknown primary site. Cancer [Internet]. 2006 Dec 1 [cited 2015 Sep 30];107(11):2698-705. Available from: http://www.ncbi.nlm.nih.gov/ pubmed/17063500

[13] Lu H-J, Chen K-W, Tzeng C-H, Liu J-H, Chiou $\mathrm{T}-\mathrm{J}$, Yen $\mathrm{C}-\mathrm{C}$, et al. Evaluation of prognosis for carcinoma of unknown origin in elderly patients. Oncology [Internet]. 2012 Jan [cited 2015 Sep 30];83(1):24-30. Available from: http://www.ncbi. nlm.nih.gov/pubmed/22722484

[14] Chen K-W, Liu C-J, Lu H-J, Tzeng C-H, Liu J-H, Chiou T-J, et al. Evaluation of prognostic factors and the role of chemotherapy in unfavorable carcinoma of unknown primary site: a 10-year cohort study. BMC Res Notes [Internet]. 2012 Jan [cited 2015 Sep 30];5:70. Available from: http:// www.pubmedcentral.nih.gov/articlerender.fcgi ?artid $=3331815 \&$ tool=pmcentrez\&rendertype $=$ abstract

[15] Penel N, Negrier S, Ray-Coquard I, Ferte C, Devos P, Hollebecque A, et al. Development and validation of a bedside score to predict early death in cancer of unknown primary patients. PLoS One [Internet]. 2009 Jan [cited 2015 Sep 30];4(8):e6483.
Available from: http://www.pubmedcentral.nih.gov/ articlerender.fcgi?artid=2715134\&tool=pmcentrez\& rendertype $=$ abstract

[16] Kodaira M, Takahashi S, Yamada S, Ueda K, Mishima Y, Takeuchi K, et al. Bone metastasis and poor performance status are prognostic factors for survival of carcinoma of unknown primary site in patients treated with systematic chemotherapy. Ann Oncol [Internet]. 2010 Jun [cited 2015 Sep 30];21(6):1163-7. Available from: http://www.ncbi. nlm.nih.gov/pubmed/20019088

[17] Fernandez-Cotarelo MJ, Guerra-Vales JM, Colina $\mathrm{F}$, de la Cruz J. Prognostic factors in cancer of unknown primary site. Tumori [Internet]. Jan [cited 2015 Sep 30];96(1):111-6. Available from: http:// www.ncbi.nlm.nih.gov/pubmed/20437867

[18] Van de Wouw AJ, Jansen RLH, Griffioen AW, Hillen HFP. Clinical and immunohistochemical analysis of patients with unknown primary tumour. A search for prognostic factors in UPT. Anticancer Res [Internet]. Jan [cited 2015 Sep 30];24(1):297301. Available from: http://www.ncbi.nlm.nih.gov/ pubmed/15015611

[19] Petrakis D, Pentheroudakis G, Voulgaris E, Pavlidis $\mathrm{N}$. Prognostication in cancer of unknown primary (CUP): development of a prognostic algorithm in 311 cases and review of the literature. Cancer Treat Rev [Internet]. 2013 Nov [cited 2015 Sep 30];39(7):701-8. Available from: http://www.ncbi. nlm.nih.gov/pubmed/23566573

[20] Trivanović D, Petkovic M, Stimac D. New prognostic index to predict survival in patients with cancer of unknown primary site with unfavourable prognosis. Clin Oncol (R Coll Radiol) [Internet]. 2009 Mar [cited 2015 Sep 30];21(1):43-8. Available from: http:// www.ncbi.nlm.nih.gov/pubmed/18976894

[21] Randén M, Helde-Frankling $M$, Runesdotter $S$, Gunvén P. Unfavorable cancers of unknown primaries: presentation and prognostic factors. A population-based 8-year experience. Med Oncol [Internet]. 2013 Dec [cited 2015 Sep 30];30(4):706. Available from: http://www.ncbi.nlm.nih.gov/ pubmed/24045931

[22] Hogan BA, Thornton FJ, Brannigan M, Browne TJ, Pender S, O'Kelly P, et al. Hepatic metastases from an unknown primary neoplasm (UPN): survival, prognostic indicators and value of extensive investigations. Clin Radiol [Internet]. 2002 Dec [cited 2015 Sep 30];57(12):1073-7. Available from: http://www.ncbi.nlm.nih.gov/pubmed/12475531

[23] Pavlidis N. Optimal therapeutic management of patients with distinct clinicopathological cancer of unknown primary subsets. Ann Oncol [Internet]. 
2012 Sep [cited 2015 Sep 30];23 Suppl 1:x282-5. Available from: http://www.ncbi.nlm.nih.gov/ pubmed/22987978

[24] Hainsworth JD, Greco FA. Management of patients with cancer of unknown primary site. Oncology (Williston Park) [Internet]. 2000 Apr [cited 2015 Sep 30];14(4):563-74; discussion 574-6, 578-9. Available from: http://www.ncbi.nlm.nih.gov/ pubmed/10826316

[25] Varadhachary G. Carcinoma of Unknown Primary Site: The Poster Child for Personalized Medicine? JAMA Oncol [Internet]. 2015 Apr 1 [cited 2015 Aug 18];1(1):19-21. Available from: http://www.ncbi. nlm.nih.gov/pubmed/26182299

[26] Hainsworth JD, Rubin MS, Spigel DR, Boccia R V, Raby S, Quinn R, et al. Molecular gene expression profiling to predict the tissue of origin and direct site-specific therapy in patients with carcinoma of unknown primary site: a prospective trial of the Sarah Cannon research institute. J Clin Oncol [Internet]. 2013 Jan 10 [cited 2015 Sep 30];31(2):217-23. Available from: http://www.ncbi. nlm.nih.gov/pubmed/23032625

[27] Greco FA. Cancer of unknown primary site: improved patient management with molecular and immunohistochemical diagnosis. Am Soc Clin Oncol Educ Book [Internet]. 2013 Jan [cited 2015 Sep 30];175-81. Available from: http://www.ncbi. nlm.nih.gov/pubmed/23714493

[28] Stella GM, Senetta R, Cassenti A, Ronco M, Cassoni P. Cancers of unknown primary origin: current perspectives and future therapeutic strategies. J Transl Med [Internet]. 2012 Jan [cited 2015 Jun 1];10:12. Available from: http://www.pubmedcentral. nih.gov/articlerender.fcgi?artid=3315427\&tool=pm centrez\&rendertype=abstract

[29] Schapira D V, Jarrett AR. The need to consider survival, outcome, and expense when evaluating and treating patients with unknown primary carcinoma. Arch Intern Med [Internet]. 1995 Oct 23 [cited 2015 Jun 1];155(19):2050-4. Available from: http://www.ncbi.nlm.nih.gov/pubmed/7575063

[30] Hamilton CS, Langlands AO. ACUPS (adenocarcinoma of unknown primary site): a clinical and cost benefit analysis. Int $\mathrm{J}$ Radiat 1 Hamilt CS, Langlands AO ACUPS (adenocarcinoma Unkn Prim site) a Clin cost benefit Anal Int J Radiat Oncol Biol Phys [Internet] 1987 Oct [cited 2015 Jun 1];13(10)1497-503 Available from ht [Internet]. 1987 Oct [cited 2015 Jun 1];13(10):1497-503. Available from: http://www.ncbi.nlm.nih.gov/ pubmed/3114181
[31] Greco FA, Oien K, Erlander M, Osborne R, Varadhachary G, Bridgewater J, et al. Cancer of unknown primary: progress in the search for improved and rapid diagnosis leading toward superior patient outcomes. Ann Oncol [Internet]. 2012 Feb [cited 2015 May 22];23(2):298-304. Available from: http://www.ncbi.nlm.nih.gov/ pubmed/21709138

[32] Pavlidis N, Pentheroudakis G, Plataniotis G. Cervical lymph node metastases of squamous cell carcinoma from an unknown primary site: a favourable prognosis subset of patients with CUP. Clin Transl Oncol [Internet]. 2009 Jun [cited 2015 Jun 1];11(6):340-8. Available from: http://www.ncbi. nlm.nih.gov/pubmed/19531448

[33] Varadhachary GR, Abbruzzese JL, Lenzi R. Diagnostic strategies for unknown primary cancer. Cancer [Internet]. 2004 May 1 [cited 2015 Jun 1];100(9):1776-85. Available from: http://www.ncbi. nlm.nih.gov/pubmed/15112256

[34] Handorf CR, Kulkarni A, Grenert JP, Weiss LM, Rogers WM, Kim OS, et al. A multicenter study directly comparing the diagnostic accuracy of gene expression profiling and immunohistochemistry for primary site identification in metastatic tumors. Am J Surg Pathol [Internet]. 2013 Jul [cited 2015 Sep 30];37(7):1067-75. Available from: http://www.ncbi. nlm.nih.gov/pubmed/23648464

[35] Oien KA, Dennis JL. Diagnosticwork-up of carcinoma of unknown primary: from immunohistochemistry to molecular profiling. Ann Oncol [Internet]. 2012 Sep [cited 2015 Sep 14];23 Suppl 1:x271-7. Available from: http://www.ncbi.nlm.nih.gov/ pubmed/22987975

[36] Varadhachary G. New Strategies for Carcinoma of Unknown Primary: The Role of Tissue-of-Origin Molecular Profiling. Clin Cancer Res [Internet]. 2013 Mar 21 [cited 2015 Sep 30];19(15):402733. Available from: http://www.ncbi.nlm.nih.gov/ pubmed/23519898

[37] Boyland L, Davis C. Patients' experiences of carcinoma of unknown primary site: dealing with uncertainty. Palliat Med [Internet]. 2008 Mar [cited 2015 Sep 30];22(2):177-83. Available from: http:// www.ncbi.nlm.nih.gov/pubmed/18372382

[38] Hyphantis T, Papadimitriou I, Petrakis D, Fountzilas G, Repana D, Assimakopoulos K, et al. Psychiatric manifestations, personality traits and health-related quality of life in cancer of unknown primary site. Psychooncology [Internet]. 2013 Sep [cited 2015 Sep 30];22(9):2009-15. Available from: http://www. ncbi.nlm.nih.gov/pubmed/23359412 